\title{
PANORAMA SOBRE A ANÁLISE ECONÔMICA DO DIREITO E SUA APLICAÇÃO
} NO BRASIL

\author{
Gabriela Borges Silva ${ }^{1}$
}

Resumo: O presente trabalho tem por objetivo traçar um panorama da escola de pensamento denominada "Análise Econômica do Direito" e sua expansão no Brasil. Para analisar as premissas da Análise Econômica do Direito, pretende-se abordar os principais aspectos para compreensão do surgimento do movimento, de sua conceituação, seus pressupostos teóricos, assim como as críticas que evidenciam suas limitações teóricas. Além disso, o trabalho propõe-se a estudar como a Análise Econômica do Direito tem sido aplicada no Brasil e de que maneira esse referencial teórico pode servir como instrumento na prática jurídica brasileira.

Palavras-chave: Análise Econômica do Direito. Eficiência. Direito da Concorrência. Racionalidade. Microeconomia.

\section{OVERVIEW ON THE ECONOMIC ANALYSIS OF LAW AND ITS APPLICATION IN BRAZIL}

Abstract: This article aims to discuss the Economic Analysis of Law and its expansion in Brazil. To comprehend the assumptions of the theoretical movement, this article intends to analyze the main aspects for understanding the emergence of the movement, its conceptualization, its characteristics, and the basic concepts of microeconomics theory - as well as criticisms that highlight its theoretical limitations. In addition, this article intends to demonstrate how the movement was incorporated in Brazil and how this theoretical framework can be helpful as an instrument in Brazilian legal practice.

Key-words: Law and economics. Efficiency. Antitrust law. Rationality. Microeconomics

\section{INTRODUÇÃO}

O movimento teórico denominado Análise Econômica do Direito "pode ser definido como a aplicação da teoria econômica - sobretudo da microeconomia e dos conceitos básicos de economia de bem-estar, para examinar a formação, estrutura, processo e impacto econômico no direito e nas instituições jurídicas (MERCURO; MEDEMA, 2006, p. 1). Inicialmente, o movimento teve como precursores economistas, tais como Gary Becker

\footnotetext{
${ }^{1}$ Doutoranda em Direito da Regulação pela FGV Direito Rio. Mestre em Direito da Regulação pela FGV Direito Rio. Pós-graduada em Direito Empresarial pela FGV Direito Rio. Bacharel em Direito pelo Centro Universitário do Estado do Pará. Advogada e pesquisadora do Centro de Pesquisa em Direito e Economia da FGV Direito Rio. Contato: gabriela.borges@fgv.br.
} 
(1957), Ronald Coase (1960) e Guido Calabresi (1961), mas aos poucos, juristas também se tornaram adeptos ao movimento, como Richard Posner.

Para o Ministro Luiz Fux e Bruno Bodart (2019, p. 22-23), a Análise Econômica do Direito (AED) é um movimento teórico que propõe a utilização de métodos científicos econômicos para o estudo de diversas expressões do comportamento humano que sejam relevantes para questões jurídicas (FUX; BODART, 2019, p. 22).

De acordo com os referidos autores, a Análise Econômica do Direito se originou e se estabeleceu como um movimento externo ao âmbito jurídico e indiferente às tradicionais concepções ao redor das quais disputavam diferentes escolas de pensamento no Direito, como formalismo, realismo, jusnaturalismo e positivismo.

Sobre esse particular, frise-se que o realismo contribuiu de forma genérica para o estudo multidisciplinar no meio jurídico, no sentido de que é impossível compreender o Direito em completa abstração da sociedade à qual este se vincula. Por sua vez, o movimento da Análise Econômica do Direito utiliza a Economia como elemento central do estudo do Direito como política pública.

Embora o movimento da Análise Econômica do Direito e o realismo jurídico sejam fundamentalmente distintos, a aplicação da teoria econômica nas instituições jurídicas não é inédita. Tanto David Hume quanto Adam Smith já discutiam o papel da Economia nas relações jurídicas, que foi posteriormente foi aprofundado por Jeremy Bentham em sua análise utilitarista dos crimes e das punições (FREIRE, 2016, p. 237).

No entanto, os verdadeiros pioneiros no que diz respeito à análise das leis que regulam comportamentos não mercadológicos foram Ronald Coase e Guido Calabresi. Somente a partir da publicação do célebre artigo de Ronald Coase intitulado "Problem of social cost" (COASE, 1960), bem como de outras obras do referido autor e também de Guido Calabresi, especialmente seu artigo "Some Thoughts on Risk Distribution and the Law of Torts" (CALABRESI, 1961), que foi possível vislumbrar uma teoria econômica do common law.

Os insights de Coase sobre custos de transação foram relevantes para vários estudiosos do movimento, principalmente para Richard Posner, que passou a desenvolver trabalhos examinando a hipótese de que a tomada de decisão racional que maximiza o uso eficiente dos recursos seria o objetivo declarado, segundo Posner, da análise econômica de problemas jurídicos (Hermann, 1974, p. 358) e que a melhor maneira de explicar o common law era entendendo os juízes como maximizadores do bem-estar econômico (2007, p. 7). 
Sendo assim, para Posner (2007), o objetivo do direito, na ótica da Análise Econômica do Direito, é o de analisar as normas de modo a promover eficiência, o que implica, consequentemente, na maximização do bem-estar social. A noção de eficiência está, portanto, intimamente ligada à maximização de bem-estar da sociedade.

Logo, considera-se determinado comportamento, proposição legislativa ou política pública eficiente quando esta proporciona um aumento de bem-estar para a sociedade. $\mathrm{O}$ raciocínio da maximização da riqueza é ilustrado pelo próprio Posner (2007, p. 477-478) da seguinte forma:

\begin{abstract}
A 'riqueza' em 'maximização da riqueza' refere-se à soma de todos os bens e serviços tangíveis e intangíveis, ponderados por dois tipos de preços: preços ofertados (o que as pessoas se predispõem a pagar por bens que ainda não possuem) e preços solicitados (o que as pessoas pedem para vender o que possuem). Se A estiver disposto a pagar até $\$ 100$ pela coleção de selos de B, ela vale $\$ 100$ para A. Se B estiver disposto a vender a coleção de selos a qualquer preço acima de $\$ 90$, ela vale $\$ 90$ para B. Portanto, se B vender a coleção de selos para A (digamos por $\$ 100$, mas qualitativamente a análise não é afetada por nenhum preço entre \$90 e \$100 - e é somente dentro desses limites de variação que a transação vai ocorrer), a riqueza da sociedade aumentará em $\$ 10$. Antes da transação, A tinha $\$ 100$ em espécie, e B tinha uma coleção de selos valendo $\$ 90$ (um total de \$190); depois da transação, A tem uma coleção de selos que vale $\$ 100$ em espécie (um total de \$200). A transação não vai aumentar a riqueza calculada - o produto interno bruto, a renda nacional ou coisas do gênero - em \$10; não vai aumentá-la em nada a menos que a transação seja contabilizada e, se assim o for, é provável que aumente a riqueza calculada ao preço de compra total de $\$ 100$. Contudo, o verdadeiro acréscimo à riqueza social consiste no incremento de $\$ 10$ em satisfação não-pecuniária que A extrai da compra, comparado ao de B.
\end{abstract}

A abordagem proposta por Posner determina que todos os custos e benefícios devem ser considerados para a tomada de decisão da norma ou conduta mais eficiente. Este trabalho parte da premissa da perspectiva de Posner sobre a Análise Econômica do Direito, a fim de realizar uma breve análise retrospectiva da origem histórica do movimento, de seus pressupostos teóricos e das ferramentas metodológicas.

Adotada essa premissa, serão analisadas as críticas direcionadas ao movimento, bem como sua evolução e o processo de adaptação para sua aplicação no direito brasileiro. Em síntese, pretende-se analisar as premissas do movimento da Análise Econômica do Direito, como tal teoria tem sido aplicada no direito brasileiro e de que maneira esse referencial teórico pode ser servir como instrumento na prática jurídica brasileira.

Para atingir tal objetivo, o trabalho analisa a definição do movimento da Análise Econômica do Direito, seus pressupostos e fundamentos teóricos. Em seguida, serão analisados os conceitos da teoria da microeconomia incorporados ao movimento para 
interpretação do Direito e de suas instituições. Feita tal análise preliminar, serão abordadas, ainda, as críticas que evidenciam as limitações teóricas e práticas no movimento.

Por fim, será realizada breve análise, por meio de fontes doutrinárias e jurisprudenciais, de aplicações práticas da Análise Econômica do Direito no Brasil, em especial no direito concorrencial, por meio do estudo de caso do Ato de Concentração n $08700.002155 / 2017-49$, apreciado pelo Tribunal Administrativo de Defesa Econômica, do Conselho Administrativo de Defesa Econômica (CADE) em 28 de fevereiro de 2018.

Pretende-se demostrar que, a despeito das críticas à Análise Econômica do Direito, o movimento pode e deve servir como instrumental, seja para auxiliar na prática jurídica dos tribunais, quanto para utilização de parâmetros e critérios em determinados institutos legais de viés fortemente econômico, como o direito concorrencial.

\section{DEFINIÇÃO E ORIGEM DA ANÁLISE ECONÔMICA DO DIREITO}

A origem do movimento (ou da escola doutrinária) chamado Law \& Economics e conhecida no Brasil como Análise Econômica do Direito ou Direito e Economia, remonta à publicação do célebre artigo de Ronald Coase intitulado "Problem of social cost" (COASE, 1960), bem como de outras obras do referido autor e também de Guido Calabresi, especialmente seu artigo "Some Thoughts on Risk Distribution and the Law of Torts" (CALABRESI, 1961).

No entanto, de uma perspectiva acadêmica, considera-se como o marco inicial da interdisciplinaridade entre o Direito e a Economia, as décadas de 1940 e 1950, quando economistas passaram a lecionar na faculdade de direito da Universidade de Chicago (GELTER; GRECHEGNIG, 2014, p. 3).

Na mesma época, Oliver Wendell Homes Jr., ex-juiz da Suprema Corte norteamericana, precursor da transposição das teses e concepções do pragmatismo filosófico para o Direito, teria sugerido que os juristas precisavam de boa dose de economia para poder conduzir o direito pelo caminho dos benefícios sociais gerais (FREIRE, 2016, p. 233).

É inegável, contudo, que o movimento somente ganhou maior notoriedade a partir da contribuição de Ronald Coase. O artigo "Problem of social cost", publicado em 1960 no The Journal of Law and Economics, trata de muitos conceitos da economia que são aplicados ao direito, como por exemplo, eficiência e custos de transação. O Teorema baseia-se na premissa 
de que indivíduos, a um custo de transação zero, podem negociar livremente para solucionar seus problemas, sem a interferência do Direito, hipótese em que o resultado será o mais eficiente (GELTER; GRECHEGNIG, 2014, p. 3).

Martin Gelter e Kristoffel Grechenig resumiram que a essência do primeiro trabalho de Ronald Coase, baseada na importância dos custos de transação, ajudou a expansão de métodos econômicos para áreas onde as aplicações de princípios econômicos não pareciam tão óbvias (2014, p. 3).

Outro importante autor para o campo da Análise Econômica do Direito é Gary Becker, economista e professor das Universidades de Princeton e Chicago, que ficou famoso por aplicar os princípios da economia à análise do crime, às questões raciais e à direito das famílias. Suas obras lhe renderam o Prêmio Nobel de ciências econômicas em 1992. Embora o interesse pelos temas jurídicos tenha se expandido entre economistas, os principais responsáveis pela popularização desse movimento nas universidades americanas, foram os acadêmicos de formação jurídica, dentre os quais pode-se mencionar como os mais proeminentes, Guido Calabresi, Henri Mane e Richard Posner.

$\mathrm{Na}$ Europa, por outro lado, as faculdades se mantiveram adeptas a conteúdos mais tradicionalistas e muito desse movimento foi e continua até hoje sendo sustentado por economistas.

É importante ressaltar que o movimento da Análise Econômica do Direito não é homogêneo. Ao contrário, como afirma Alejandro Bugallo Alvarez, a Análise Econômica do Direito congrega várias tendências, tais como (i) conservadora, relacionada à Escola de Chicago identificada com a figura de Richard Posner e integrada, dentre outros, por Landes, Schwartz, Kitch e Easterbrook; (ii) a liberal-reformista, com Calabresi como figura representativa e integrada por uma diversidade de autores como Polinsky, Ackermann, Korhnhauser, Cooter e Coleman; e (iii) tendência neoinstitucionalista, que se distingue das anteriores tanto na temática como na metodologia e tem como adeptos, entre outros, por A. Allam Schmid, Warren J. Samuels, Nicholas Mercúrio e Oliver E. Williamson (ALVAREZ, 2006, p. 49).

Richard Posner, um dos teóricos mais conhecidos da Análise Econômica do Direito, publicou sua monografia "Economic Analysis of Law”, enquanto professor na Universidade de Chicago (POSNER, 1973). A análise de Posner é desenvolvida sob os postulados fundamentais de economia neoclássica. $\mathrm{O}$ autor foi o primeiro a relacionar a maior parte dos ramos do direito a uma análise sistemática sob a perspectiva econômica, baseando-se 
particularmente no trabalho de Ronald Coase e do problema dos custos sociais (Hermann, 1974, p. 358). Dentre as inúmeras ideias instigantes de Posner nessa obra, talvez a mais polêmica seja de que a eficiência deveria ser considerada como a medida de maximização da riqueza, de modo que Posner não considerava outras medidas de valor como a justiça, por exemplo, como maximizadores do bem-estar da sociedade (GELTER; GRECHEGNIG, 2014, p. 4).

De acordo com Alonso Freire a expansão da Análise Econômica do Direito foi facilitada pela aplicação do instrumental econômico ao comportamento não mercadológico. $\mathrm{O}$ autor defende que a concepção da análise econômica de Posner somente se tornou difundida porque anteriormente Ronald Coase e Guido Calabresi difundiram a aplicação da economia à análise das leis que regulam comportamentos não mercadológicos (FREIRE, 2016).

Na concepção do Ministro Luiz Fux e de Bruno Bodart, a Análise Econômica do Direito vai além da mera interseção entre a Economia e o campo jurídico, tratando-se, na realidade, da expansão do método científico adotado no estudo da Economia, para o desenvolvimento do pensamento jurídico, ainda fortemente influenciado pela visão do Direito de uma perspectiva dogmática e tradicionalista (2019, p. 2-3).

A teoria econômica tem por base o modelo de escolha racional, segundo o qual os indivíduos têm toda a capacidade racional necessária para escolher o melhor curso da ação (HINDMOOR; TAYLOR, 2015), portanto, a partir dessa concepção, os indivíduos são agentes econômicos racionais, que tomarão decisões por meio de ponderação de custos e benefícios, baseadas em preferências individuais existentes, de forma mais eficiente (MODIGLIANI; ANDO, 1963, p. 153).

Muitas críticas foram realizadas sobre a aplicação da teoria da escolha racional para questões jurídicas que serão aprofundadas na próxima sessão. Cumpre ressaltar, de antemão, que o movimento contemporâneo da Análise Econômica do Direito incorporou diversas críticas, como por exemplo as relacionadas as questões de eficiência (GELTER; GRECHEGNIG, 2014, p. 6).

No Brasil, conforme argumentam Armando Castelar Pinheiro e Jairo Saddi, desde o advento da Constituição Federal de 1988 e a proliferação de planos econômicos na década de 80, cresceu também o embate entre Direito e Economia no Brasil (PINHEIRO; SADDI, 2006, p. 49). Mais especificamente, segundo os autores, isso decorreu das novas atribuições conferidas pela Carta Magna ao Poder Judiciário, assim como da presença de dispositivos 
constitucionais que atribuíram ao Estado a prerrogativa de prover serviços públicos universais aos cidadãos e às cidadãs.

\section{PREMISSAS E PRINCIPAIS CARACTERÍSTICAS DA ANÁliSE ECONÔMICA DO DIREITO}

Nesta seção serão apresentadas as principais características do movimento denominado Análise Econômica do Direito, de modo a facilitar a melhor compreensão a respeito de seu propósito, tanto para fins acadêmicos, quanto para fins de aplicabilidade prática em diversas áreas jurídicas.

\subsection{A teoria microeconômica e a Análise Econômica do Direito}

A Análise Econômica do Direito é uma disciplina que estuda o direito e suas instituições, tendo como eixo central de análise a racionalidade individual, como mencionado na seção anterior. Na análise de Porto, o movimento pode ser conceituado como a "aplicação da teoria econômica, e dos métodos econométricos, no exame da formação, da estrutura, dos processos e dos impactos do direito e das instituições legais" (PORTO, 2019, p. 28).

A perspectiva teórica em questão fundamenta-se em métodos da teoria microeconômica. Segunda tal teoria, antes da tomada de decisões os agentes econômicos comparam os benefícios e os custos das diferentes alternativas. Essa análise de custos e benefícios ocorre a partir das preferências dos agentes e do conjunto de informações disponíveis no momento da avaliação (PORTO, 2019, p. 28).

De acordo com Porto, a Análise Econômica do Direito é, portanto, a aplicação de uma perspectiva de "eficiência" às normas jurídicas (PORTO, 2019, p. 28). O autor defende que a suposição que permeia a Análise Econômica do Direito é que a jurisprudência deveria avaliar as normas e os preceitos legais de acordo com um critério que determinasse se eles facilitam ou atrapalham o uso eficiente dos recursos conforme o seu custo, ou seja, a partir da avaliação do custo-benefício. Quando se analisam as normas de acordo com o grau em que facilitam o uso de recursos escassos, avalia-se as consequências que terão efeitos sobre toda sociedade. Nesse sentido, a Análise Econômica do Direito pertence ao que é conhecido como ética consequencialista (OTT, SHÄFER; 2004). 
Porto sustenta, ainda, que para a Análise Econômica do Direito, a avaliação custobenefício parte de um contexto determinado de preferências que se traduz em um nível de bem-estar dos agentes e é medido pela utilidade que retira da sua decisão, bem como das escolhas que poderia ter feito e não fez (os custos de oportunidade ${ }^{2}$ ) (PORTO, 2019, p. 28).

$\mathrm{O}$ referido autor traça, por fim, um paralelo entre as perspectivas da interação entre Direito e Economia segundo o qual a perspectiva econômica enxerga o direito como uma instituição que deve promover a eficiência, contribuindo, dessa forma, para melhorar o bemestar social.

No entanto, na concepção da Análise Econômica do Direito, o Direito não deve ser usado para corrigir aspectos de distribuição de riqueza ou desigualdade social. Deve, no entanto, estar associado instrumentalmente com outras áreas de saber, para que possa promover elementos distributivos. Mecanismos como a política fiscal ou orçamentária, por exemplo, podem corrigir esses aspectos com um menor custo social (PORTO, 2019, p. 30).

De acordo com Fux e Bodart (2019, p. 14), o eixo central da Economia moderna assume que indivíduos possuem preferências logicamente ordenadas, sendo que o grau de atendimento dessas preferências tem influência no seu bem-estar, de modo que para fins de políticas públicas, busca-se estabelecer, por meio de estudos econômicos, qual escolha deve a sociedade adotar diante de diversas opções alocativas.

A definição de distribuição de recursos mais recorrente na literatura econômica do bem-estar é o critério de Pareto, segundo o qual uma distribuição de recursos será eficiente se não for possível distribuir recursos de forma que pelo menos uma pessoa tenha sua situação melhorada e nenhuma outra tenha sua situação piorada.

Uma distribuição eficiente de recursos é chamada "Ótimo de Pareto". Esse critério requer que os ganhadores compensem explicitamente os perdedores em qualquer mudança. Tal raciocínio forma o núcleo da legitimidade do mercado como um mecanismo alocativo, pois mostra que alocações alcançadas em equilíbrio competitivo são perfeitamente eficientes e assim produzem resultados positivos de bem-estar para a sociedade (COOTER; ULLEN, 2010, p. 64).

Posteriormente, foi desenvolvida pelos economistas a noção de uma melhoria potencial de Pareto (denominada "eficiência Kaldor-Hicks"), na qual permite-se mudanças tanto para os ganhadores, quanto para perdedores, mas exige que os ganhadores ganhem mais

\footnotetext{
${ }^{2}$ Os custos de oportunidade consistem na diferença entre a opção escolhida e a melhor opção não escolhida em um processo de decisão.
} 
do que os perdedores perdem. Se essa condição for cumprida, os ganhadores podem indenizar os perdedores e ainda se beneficiar de um excedente. Trata-se basicamente de uma análise de custo-benefício. $\mathrm{Na}$ análise de custo-benefício, um projeto é empreendido quando seus benefícios excedem seus custos, o que implica que os ganhadores poderiam compensar os perdedores (PORTO, 2019, p. 64-65).

\subsection{Críticas à Análise Econômica do Direito}

Conforme mencionado anteriormente, a teoria da escolha racional não está imune a críticas e diversos pesquisadores têm questionado suas premissas, com base em conclusões sobre o comportamento humano, concluídas a partir de pesquisas empíricas.

A principal crítica com relação a utilização dos critérios adotados pela Análise Econômica do Direito para distribuição de recursos e para o alcance do bem-estar social são os parâmetros para auferir a eficiência a partir de uma visão estritamente econômica, sem considerar noções de justiça e moralidade na tomada de decisões, defendidas por alguns autores como Dworkin.

Dworkin questiona se a teoria da eficiência implica em buscar a riqueza social porque a riqueza é um valor por si (componente de valor) ou porque é instrumento. Em sua concepção, a riqueza não é um componente de valor, tendo em vista que a eficiência está relacionada à distribuição igualitária dos recursos ${ }^{3}$. Dessa forma, Dworkin rejeita a tese do princípio da eficiência como valor em si.

Teoricamente, vale destacar que a Análise Econômica do Direito evoluiu e incorporou as críticas realizadas durante as últimas décadas. A principal delas é focada no conceito de eficiência e da escolha racional. A racionalidade ainda é colocada como aspecto central nessas teorias, mas já há discussões de análise econômica sob um viés comportamental.

Nesse sentido, segundo Fux e Bodart (2019, p.17), na perspectiva dos entusiastas da corrente "comportamental", critica-se a presunção de que indivíduos são capazes de valorar situações em uma ordem lógica de preferências, em razão de inconsistências verificadas em experimentos empíricos. Essa vertente comportamental do movimento da Análise Econômica

\footnotetext{
${ }^{3}$ DWORKIN travou discussões com Calabresi e Posner, tratando as questões da eficiência e justiça, nas seguintes obras: Taking Rights Seriously. Londres: Gerald Duckworth \& Co.Ltd., 1977; O império do direito. São Paulo: Martins Fontes, 1999; Uma questão de princípio. São Paulo: Martins Fontes, 2000; A virtude soberana: teoria e prática da igualdade. São Paulo: Martins Fontes, 2005.
} 
pretende avaliar até que ponto certas falhas cognitivas podem ter importância na análise positiva e normativa do direito.

Nesse sentido, Porto e Thevenard afirmam que o principal fundamento da economia comportamental consiste na afirmação de que "os indivíduos, em geral, não tomam decisões em conformidade com os padrões de racionalidade estabelecidos pela teoria econômica clássica, mas, ao invés disso, adotam 'atalhos' ou heurísticas, que consistem em mecanismos simplificados de solução de problemas complexos" (PORTO, THEVENARD, 2012, p. 5176).

É possível, ainda, citar como as principais críticas à análise de custo-benefício: (i) a métrica estritamente monetária, que acaba se mostrando inadequada para a aferição do valor de determinados bens jurídicos; (ii) o parâmetro monetário, que é considerado por parte da academia como meramente utilitarista, sem a existência de preocupações éticas (PORTO, THEVENARD, 2012, p. 51-76).

\section{Aplicação da Análise Econômica do Direito no direito brasileiro}

Como visto nas últimas seções deste trabalho, em geral, o direito e a economia fornecem subsídios para a compreensão de como a formulação das regras jurídicas pode modificar a realidade na prática, possibilitando a antecipação das consequências, da modificação das leis e de outros normativos e procedimentos.

Além disso, é possível utilizar a teoria econômica para analisar proposições legislativas, normas jurídicas e políticas públicas, por meio de critérios metodológicos baseados na microeconomia.

O estudo da Análise Econômica do Direito vem se desenvolvendo bastante dentro do Direito Civil brasileiro, principalmente nos ramos do Direito de Propriedade, Direito Contratual e na Responsabilidade Civil, áreas nas quais o movimento da Análise Econômica do Direito já é muito forte nos Estados Unidos (RUBIN, 2018). Novos autores começam a usar essa metodologia em seus livros e tratados.

No âmbito do Judiciário, o Superior Tribunal de Justiça - STJ e outros tribunais do país têm utilizado com cada vez mais frequência o raciocínio de Análise Econômica do Direito para tomar decisões. Uma decisão que se afigura como marco desse movimento é o 
Recurso Especial $\mathrm{n}^{\mathrm{o}} 1163283 / \mathrm{RS}^{4}$, no qual o Superior Tribunal de Justiça decidiu da seguinte maneira:

\begin{abstract}
RECURSO ESPECIAL. PROCESSUAL CIVIL. CONTRATOS DE FINANCIAMENTO IMOBILIÁRIO. SISTEMA FINANCEIRO DE HABITAÇÃO. LEI N. 10.931/2004. INOVAÇÃO. REQUISITOS PARA PETIÇÃO INICIAL. APLICAÇÃO A TODOS OS CONTRATOS DE FINANCIAMENTO. 1. A análise econômica da função social do contrato, realizada a partir da doutrina da análise econômica do direito, permite reconhecer o papel institucional e social que o direito contratual pode oferecer ao mercado, qual seja a segurança e previsibilidade nas operações econômicas e sociais capazes de proteger as expectativas dos agentes econômicos, por meio de instituições mais sólidas, que reforcem, ao contrário de minar, a estrutura do mercado. 2 . Todo contrato de financiamento imobiliário, ainda que pactuado nos moldes do Sistema Financeiro da Habitação, é negócio jurídico de cunho eminentemente patrimonial e, por isso, solo fértil para a aplicação da análise econômica do direito. 3. A Lei n. 10.931/2004, especialmente seu art. 50, inspirou-se na efetividade, celeridade e boa-fé perseguidos pelo processo civil moderno, cujo entendimento é de que todo litígio a ser composto, dentre eles os de cunho econômico, deve apresentar pedido objetivo e apontar precisa e claramente a espécie e o alcance do abuso contratual que fundamenta a ação de revisão do contrato. 4. As regras expressas no art. 50 e seus parágrafos têm a clara intenção de garantir o cumprimento dos contratos de financiamento de imóveis tal como pactuados, gerando segurança para os contratantes. $\mathrm{O}$ objetivo maior da norma é garantir que, quando a execução do contrato se tornar controvertida e necessária for a intervenção judicial, a discussão seja eficiente, porque somente o ponto conflitante será discutido e a discussão da controvérsia não impedirá a execução de tudo aquilo com o qual concordam as partes. 5. Aplicam-se aos contratos de financiamento imobiliário do Sistema de Financiamento Habitacional as disposições da Lei n. 10.931/2004, mormente os referentes aos requisitos da petição inicial da ação de revisão de cláusulas contratuais, constantes do art. 50 da Lei n. 10.931/2004. 6. Recurso especial provido. (grifo nosso).
\end{abstract}

Outro exemplo interessante dessa racionalidade é representado por uma das ações judicias decorrentes da reforma da legislação trabalhista. No âmbito da ADI $5.766^{5}$, que tramita perante o Supremo Tribunal Federal, a Procuradoria-geral da República questionou a juridicidade de três artigos da Lei $n^{\circ} 13.467 / 2017$, que impõem ao reclamante derrotado em juízo o pagamento de custas processuais e honorários advocatícios e periciais de sucumbência. Em seu voto, o Ministro Roberto Barroso considerou que o sistema anterior fornecia incentivos exagerados à litigância, motivo pelo qual o "direito à gratuidade de justiça pode ser regulado de forma a desincentivar a litigância abusiva, inclusive por meio da cobrança de custas e de honorários a seus beneficiários".

\footnotetext{
${ }^{4}$ BRASIL. SUPERIOR TRIBUNAL DE JUSTIÇA. RESP 1.163.283 - RS (2009/0206657-6). Ministro Relator Luis Felipe Salomão. Quarta Turma. Julgado em 07.04.2015. DJe 04.05.2015.

${ }^{5}$ BRASIL. SUPERIOR TRIBUNAL FEDERAL. AÇÃO DIRETA DE INCONSTITUCIONALIDADE $\mathrm{N}^{\circ}$ 5.766. Ministro Relator: Roberto Barroso. Disponível em: <http://portal.stf.jus.br/processos/detalhe.asp?incidente=5250582>. Acesso em: 23 de setembro de 2019.
} 
De acordo com o Ministro Luiz Fux e Bruno Bodart (2019, p. 37), o impacto das mudanças nas regras de distribuição dos custos de litigância, reduziu dramaticamente o número de novas ações naquele ramo no Judiciário.

Além dos mencionados exemplos da aplicação da Análise Econômica do Direito no âmbito do Judiciário, a produção acadêmica sobre o movimento e suas aplicações tem se intensificado nos últimos anos. Em artigo intitulado "Spread bancário e enforcement contratual: hipótese de causalidade reversa e evidência empírica", o autor Bruno Salama (2017) faz uso de critérios econômicos para uma análise empírica acerca de sua hipótese de causalidade reversa, de que o alto spread também induz o baixo nível de adimplemento contratual.

Dentre as diversas áreas do Direito que podem se beneficiar do estudo da Análise Econômica do Direito, destaca-se o direito da concorrência. Richard Posner observou que "até os anos 1960, a análise econômica do direito era quase sinônimo de análise econômica do direito antitruste" (POSNER, 1998, p. 25). O autor embasou-se em casos de antitrustes como grandes fontes precursoras do movimento em 1960, por toda a relevância econômica da matéria e pela maneira com que os economistas os usavam para fazer uma análise econômica da regulação. Esta área de investigação continua hoje muito popular e será abordada nas seções seguintes.

\subsection{Falha de mercado: competição imperfeita}

Os mercados de concorrência perfeita são um modelo-base para a teorização da microeconomia acerca dos diferentes tipos de mercado. Para que seja considerado perfeitamente competitivo, deve apresentar determinadas características: nele, os produtos devem ser substitutos perfeitos, ou seja, o produto vendido por um fornecedor deve ser idêntico ao ofertado por qualquer outro.

Além disso, tanto os produtores quanto os fornecedores são tomadores de preço (price-takers), o que quer dizer que, individualmente, não têm poder de mercado suficiente para influenciar o preço. Do mesmo modo, todos os recursos são perfeitamente transmissíveis de uma parte para outra, ainda que haja algum tipo de gasto para isso. Ainda, os agentes econômicos entram e saem de forma livre nesse tipo de mercado. Por fim, o fluxo de informações é perfeito no âmbito desse mercado. 
Em termos mais sintéticos, Mankiw apresenta-o como "um mercado com muitos compradores e vendedores negociando produtos idênticos, de modo que cada comprador e cada vendedor é um tomador de preço " (MANKIW, 2001).

A microeconomia, portanto, ocupa-se do estudo das causas de falhas de mercado e dos possíveis meios para corrigi-las. De acordo com a teoria econômica, o conceito de falha de mercado refere-se a circunstâncias específicas que levam um sistema de livre mercado à alocação ineficiente de bens e serviços. As imperfeições refletem desvios das condições ideais de um sistema competitivo: indivíduos e organizações, que buscam maximizar seus interesses próprios, passam a agir em dissonância com o interesse social.

Desse modo, falhas de mercado podem ser vistas como situações em que a atuação em busca de seu puro interesse particular leva a resultados não eficientes. São frequentemente associadas a assimetrias de informação, estruturas não competitivas dos mercados, problemas de monopólio natural, externalidades ou bens públicos. A sua existência é muitas vezes usada como justificativa para a intervenção governamental em um mercado particular.

De acordo com Patrícia Sampaio, a teoria econômica aponta que situações próximas às de monopólio são almejadas pelos agentes econômicos por permitir-lhes, por meio da redução da oferta e do aumento dos preços, auferir lucros superiores aos que obteriam em uma situação de concorrência (SAMPAIO, 2019, p. 28).

Por isso, tal análise desempenha um papel importante no que se refere às decisões sobre políticas públicas. No entanto, alguns tipos de intervenções e de políticas governamentais, tais como impostos, subsídios, controles de preços e salários e regulamentos, que podem constituir tentativas públicas de corrigir falhas de mercado, também podem levar a alocações ineficientes de recursos (às vezes chamadas de falhas de governo). Nesses casos, há uma escolha entre os resultados imperfeitos, isto é, os do mercado imperfeito, com ou sem intervenções do governo. Em qualquer caso, por definição, se existe uma falha de mercado o resultado não é Pareto-eficiente.

Nota-se, ainda, que em mercados que se aproximam do modelo de concorrência perfeita, os preços são resultado da interação dos agentes no mercado, de forma que os produtores não conseguem cobrar preços supracompetitivos. Conforme sintetizaram Joseph Stiglitz e Carl Walsh: "o preço e a quantidade de equilíbrio em um mercado competitivo levam ao nível mais alto possível de excedente total” (STIGLITZ; WALSH, p. 169). 


\subsection{A relação da Análise Econômica do Direito com o Direito da Concorrência}

As falhas de mercado mencionadas na seção anterior podem ser corrigidas ou diminuídas a partir da atuação das instituições. Esses ajustes podem ocorrer de diversas formas, como por meio da regulação, do fomento e da fiscalização.

Nesse sentido, pode-se afirmar que a competição entre agentes econômicos não constitui uma decorrência necessária da "natureza" dos mercados, mas, antes, pode ser atribuída ao resultado de uma política econômica, com suporte em normas jurídicas, a qual proíbe os agentes de adotarem condutas tendentes à monopolização ou de abusarem de eventual posição dominante que já apresentem em um determinado mercado (HOVENKAMP, p. 3).

No Brasil, o Conselho Administrativo de Defesa Econômica (CADE), disciplinado pela Lei $\mathrm{n}^{\circ} 12.529 / 2011$, possui esse papel, atuando como uma autarquia federal vinculada ao Ministério da Justiça que tem como função principal fiscalizar a ação dos agentes no mercado, prevenindo e reprimindo práticas comerciais contrárias à livre concorrência.

A literatura jurídica (SAMPAIO, 2019) observa que, quanto maior o poder de mercado de um agente econômico, maior a probabilidade de que este venha a abusar desse poder ou, ainda, comportar-se como um monopolista, reduzindo a oferta e aumentando os preços.

Daí surge a justificativa que enseja a intervenção do CADE como entidade reguladora para atuar tanto na repressão de condutas anticompetitivas, quanto no controle de atos de concentração de mercado.

A Análise Econômica do Direito serve, portanto, ao Direito Concorrencial como instrumento para avaliar os níveis de concentração ou as condutas competitivas abusivas que distorcem os preços de um determinando mercado, prejudicando o consumidor final e por consequência, o próprio mercado em si.

É preciso considerar, dentre outros fatores, que o poder de mercado do agente econômico, ou seja, a sua capacidade de adotar uma estratégia monopolística, sem perda de receita, depende fundamentalmente da elasticidade da demanda do produto ofertado.

Caso a elasticidade de demanda seja elevada, os consumidores se mostrarão sensíveis às variações de preço, modificando seus hábitos de consumo para um produto substituto. Todavia, caso a elasticidade seja baixa, o agente econômico poderá cobrar preços supracompetitivos sem experimentar perda significativa de demanda. 
Além disso, na análise de atos de concentração, também é preciso considerar o nível de contestabilidade do mercado afetado pelo ingresso de novos agentes, na hipótese de um aumento significativo e não transitório de preços praticado após um ato de concentração.

Nesse sentido, a partir da definição do mercado relevante da operação, do poder econômico detido pelas partes envolvidas antes e após o ato, bem como dos efeitos pretendidos ou potencializados com a concentração econômica evidenciada, a autoridade antitruste pode concluir sobre o risco de produção de efeito líquido negativo sobre o bemestar social, a justificar restrições (ou mesmo a vedação da operação) ou, contrariamente, se são observados ganhos de eficiência que justifiquem sua aprovação incondicional.

Logo, por meio do controle dos atos de concentração, as autoridades de defesa da concorrência buscam evitar, na sua origem, a formação de posições dominantes que possam ser utilizadas abusivamente no futuro, com inegáveis efeitos deletérios à sociedade. Dessa forma, justifica-se a necessidade do controle estrutural dos mercados, paralelamente ao aspecto repressivo inerente à tutela da concorrência.

O Direito da Concorrência, portanto, utiliza de ferramentas da microeconomia para identificar os atos de concentração e definir o poder de mercado de um competidor, a fim de verificar a viabilidade econômica de determinada operação, dentro de uma perspectiva de equilibro do mercado, almejando o bem-estar social.

\subsection{Aplicação prática da utilização da análise econômica pelo Direito da Concorrência}

A fim de ilustrar a aplicação da análise econômica pelo Direito da Concorrência, pretende-se realizar uma breve análise do Ato de Concentração n ${ }^{\circ}$ 08700.002155/2017-49 apreciado pelo Tribunal Administrativo de Defesa Econômica (órgão do CADE) em 28 de fevereiro de 2018, no qual o restou deliberado, por maioria, o veto à aquisição de $100 \%$ do capital social da Liquigás pela Ultragaz, sob o argumento de que a operação poderia gerar riscos de impactos negativos para os consumidores.

A operação em questão tratava-se de proposta de aquisição, pela Ultragaz, da totalidade de ações representativas do capital social da Liquigás, na época detidas pela Petrobras. As requerentes alegavam que a estratégia de diferenciação e excelência operacional

\footnotetext{
${ }^{6}$ CADE. Tribunal do Conselho Administrativo de Defesa Econômica. Procedimento Ordinário. Ato de Concentração n ${ }^{\circ}$ 08700.002155/2017-49. Disponível em: 〈http://www.cade.gov.br〉. Acesso em 13 de setembro de 2019.
} 
da Ultragaz, combinadas com a estrutura de ativos e rede da Liquigás resultariam em sinergias e ganhos significativos de eficiência em produção, logística, gestão administrativa e práticas de operação.

Foram utilizados métodos quantitativos econômicos tradicionais para verificar a possibilidade de exercício de poder de mercado, unilateral e coordenado, por meio dos quais foi possível verificar que a compra da Liquigás elevaria a possibilidade da Ultragaz exercer sua posição dominante no mercado de Gás Liquefeito de Petróleo (GLP).

De acordo com o voto da Conselheira Relatora Cristiane Alkmin Junqueira Schmidt, a Ultragaz e Liquigás detinham, respectivamente, a maior e a segunda maior participação de mercado nacional de GLP. Em um cenário pós-operação, a participação conjunta das duas sociedades responderia por mais de $40 \%$ das vendas em vários estados do país. Sendo assim, a partir da análise de concentração do mercado, constatou-se que a operação eliminaria um agente econômico relevante na maior parte dos estados brasileiros, tornando o mercado ainda mais concentrado.

Nesse sentido, a Coordenação-Geral de Análise Antitruste consignou em seu parecer que a operação suscitava preocupações concorrenciais relevantes quanto ao exercício unilateral e coordenado de poder de mercado, que não foram afastadas pelo aprofundamento da análise. Observou-se, assim, que os supostos benefícios da operação não superam os prejuízos decorrentes da eliminação da concorrência. $\mathrm{O}$ bem-estar do consumidor tenderia a diminuir, já que as eficiências alegadas, ainda que fossem específicas, não seriam suficientes, tampouco tenderiam a ser transferidas aos consumidores. Ou seja, a presente operação não resulta em eficiências antitruste.

Para compreender efetivamente de que modo ocorre a análise econômica dos atos de concentração nesta operação, é preciso analisar o art. $88, \S 5^{\circ}$ e $6^{\circ}$, da Lei 12.529/2011, que determina que:

"§ $5^{\circ}$ Serão proibidos os atos de concentração que impliquem eliminação da concorrência em parte substancial de mercado relevante, que possam criar ou reforçar uma posição dominante ou que possam resultar na dominação de mercado relevante de bens ou serviços, ressalvado o disposto no $\S 6$ deste artigo. "

Desse modo, para avaliar determinado ato de concentração, o CADE analisa a correspondente operação em 4 ou 5 etapas: (i) definição do mercado relevante; (ii) análise do nível de concentração horizontal, que aponta se é possível que o novo agente econômico tenha condições de exercer o seu poder de mercado; (iii) avaliação da probabilidade do uso de poder 
de mercado adquirido por meio de maior concentração da operação; (iv) avaliação do poder de compra existente no mercado ou criado pela operação, quando for o caso de se tratar de mercado de insumo; (v) ponderação das eficiências econômicas inerentes ao ato de concentração.

Além disso, é preciso ponderar as eficiências específicas de cada operação com os seus efeitos negativos. Ou seja, cabe avaliar se a operação gera efeito líquido não negativo sobre o bem-estar econômico dos consumidores.

O Guia para Análise de Atos de Concentração Horizontal, sumariza os critérios que o CADE adota para considerar as eficiências geradas pela operação: (i) benefícios prováveis e verificáveis; (ii) bem-estar do consumidor; (iii) eficiências específicas; e (iv) as externalidades (CONSELHO ADMINISTRATIVO DE DEFESA DA CONCORRÊNCIA, 2016).

Portanto, a metodologia econômica serviu como base para análise da viabilidade jurídica da operação. No voto da Conselheira Polyanna Ferreira Silva Vilanova foi ressaltado a necessidade de utilização de parâmetros técnicos nas tomadas de decisões de aspecto concorrencial, sendo ressaltado que em 2010 a Comissão Europeia editou o documento "Best practices for the submission of economic evidence and data collection in cases concerning the application of Articles 101 and 102 TFEU and in Merger cases" (COMISSÃO EUROPEIA, 2010).

De acordo com tal documento, é preciso estabelecer standards econômicos para auxiliar as autoridades na tomada de decisão, sendo necessário (i) garantir que a análise econômica atinja certas normas técnicas mínimas no início, (ii) facilitar a coleta e troca efetiva de fatos e evidências, em particular os dados quantitativos subjacentes, e (iii) usar de forma efetiva provas confiáveis e relevantes obtidas durante o procedimento administrativo, sejam elas quantitativas ou qualitativas (COMISSÃO EUROPEIA, 2010).

\section{CONCLUSÃO}

A Análise Econômica do Direito é uma linha de pensamento desenvolvida a partir de estudos seminais de economistas e juristas sobre a utilização da Economia como um elemento central para o Estudo do Direito, tendo como base a racionalidade individual. 
O presente trabalho pretendeu abordar os principais aspectos para compreensão do surgimento do movimento, de sua conceituação, seus pressupostos teóricos, alguns conceitos básicos da teoria microeconômica e as críticas contemporâneas.

A partir da contextualização do movimento, analisou-se, ainda, a incorporação de suas referências teóricas no Brasil e de que modo o Judiciário e a Doutrina têm adotado critérios econômicos e referências ao movimento na aplicação do Direito. Foi possível abstrair de tal análise, as seguintes conclusões:

(i) embora houvesse estudos preliminares sobre a interdisciplinaridade do Direito com outras áreas do saber, o movimento denominado Análise Econômica do Direito somente ganhou maior notoriedade a partir da contribuição de Ronald Coase, que abordou de maneira inédita a aplicação ao direito de muitos conceitos da economia, como a eficiência e os custos de transação;

(ii) Richard Posner sustenta a hipótese de que os institutos da common law evoluíram no sentido de prover incentivos para uma maior eficiência econômica, isto é, a maximização da riqueza medida em padrões monetários;

(iii) a Análise Econômica do Direito tem por base os métodos da teoria microeconômica, segundo os quais os agentes comparam os benefícios e os custos para a tomada de decisões. Os custos, por sua vez, são avaliados a partir das preferências dos agentes e da informação disponível no momento. Essa análise de custo-benefício pressupõe o modelo do agente racional;

(iv) há limitações ao modelo, seja pelos critérios utilizados para auferir o bem-estar social e a eficiência, seja pelas limitações cognitivas dos indivíduos, que possuem comportamentos individuais influenciados por normas sociais e psicológicas alheias ao modelo econômico racional;

(v) ainda que seja possível observar crescimento dos estudos sobre Análise Econômica pelo mundo e no Brasil, a temática ainda é pouco difundida e aplicada no meio jurídico brasileiro; e

(vi) o Direito da Concorrência utiliza de ferramentas da microeconomia para identificar os atos de concentração e definir o poder de mercado de um competidor, a fim de verificar a viabilidade econômica de determinada operação, dentro de uma perspectiva de equilibro do mercado, almejando o bem-estar social. 


\section{REFERÊNCIAS BIBLIOGRÁFICAS}

ALVAREZ, Alejandro Bugallo. Análise econômica do direito: contribuições e desmistificações. Direito, Estado e Sociedade. v. 9. n. 29, p. 49-68. Jul/dez, 2006.

BRASIL. SUPERIOR TRIBUNAL FEDERAL. AÇÃO DIRETA DE INCONSTITUCIONALIDADE N ${ }^{\circ}$ 5.766. Ministro Relator: Roberto Barroso. Disponível em: $<$ http://portal.stf.jus.br/processos/detalhe.asp?incidente=5250582>. Acesso em: 23 de setembro de 2019.

BECKER, Gary S.. The economics of discrimination: an economic view of racial discrimination. University of Chicago, 1957.

BUCHANAN, James M. Buena Economia. Mal Derecho. In: ROEMER, Andrés (org.). Derecho y Economia: una revisión de la Literatura. México: Fondo de Cultura Económica, 2000 .

CALABRESI, Guido. Some thoughts on risk distribution and the law of torts. The Yale Law Journal, v. 70, n. 4, p. 499-553, 1961.

COMISSÃO EUROPEIA. Competition, Directorate General. Best practices for the submission of economic evidence and data collection in cases concerning the application of articles 101 and 102 TFEU and in merger cases. 2010.

COASE, Ronald $\mathrm{H}$. The problem of social cost. In: Classic papers in natural resource economics. Palgrave Macmillan, London, 1960. p. 87-137.

COOTER, Robert; ULEN, Thomas. Direito \& Economia. Porto Alegre. Brookman Companhia Editora. 5a ed., 2010.

CONSELHO ADMINISTRATIVO DE DEFESA DA CONCORRÊNCIA. Guia para Análise de Atos de Concentração Horizontal. 2016. Disponível em:http://www.cade.gov.br/acesso-ainformacao/publicacoes-institucionais/guias_do_Cade/guia-para-analise-de-atos-deconcentracao-horizontal.pdf/view. Acesso em 25.09.2019.

Tribunal do

Conselho Administrativo de Defesa Econômica. Procedimento Ordinário. Ato de Concentração n ${ }^{\circ}$ 08700.002155/2017-49. Disponível em: 〈http://www.cade.gov.br>. Acesso em 13 de setembro de 2019.

FREIRE, Alonso. O Pêndulo de Posner. Revista Pensamento Jurídico. v. 8, n. 2, 2016.

FUX, Luiz. BODART, Bruno. Processo civil e análise econômica. Rio de Janeiro: Forense, 2019 .

GELTER, Martin; GRECHENIG, Kristoffel. History of Law and Economics. Bonn: Preprints of the Max Planck Institute for Research on Collective Goods, 2014. 
HERMANN, Donald H.J. Review of "Economic Analysis of Law," By Richard A. Posner. Washington University Law Review. v. 2. 1974.

HINDMOOR, Andrew; TAYLOR, Brad. Rational choice. Palgrave, 2015.

HOVENKAMP, Herbert. Federal antitrust policy: the law of competition and its practice. St. Paul: West Group, 1999.

MANKIW, N. Gregory. Introdução à economia: princípios de micro e macroeconomia. Rio de Janeiro: Campus, 2001.

MERCURO, Nicholas; MEDEMA, Steven G. Economics and the law: From Posner to postmodernism and beyond. Princeton University Press, 2006.

MODIGLIANI, Franco; ANDO, A. The 'life cycle' hypothesis of saving: aggregate implications and tests. American Economic Review, v. 53, 1963.

OTT, Claus; SCHÄFER, H. B. The economic analysis of civil law. Cheltenham, UK: Edward Elgar Publishing, 2004.

OLIVEIRA, Gesner; RODAS, João Grandino. Direito e economia da concorrência. Rio de Janeiro: aRenovar, 2004.

POSNER, Richard A. An Economic Approach to Legal Procedure and Judicial Administration. The Journal of Legal Studies, v.2, 1973.

1477, 1998. .An economic approach to the law of evidence. Stanford Law. Review., v. 51, p. Economic Analysis of Law. 7ed. Nova York: Aspen Publishers, 2007.

PORTO, Antônio José Maristrello; THEVENARD, Lucas. Economia Comportamental e Contratos de Adesão. Revista Direito Empresarial (Curitiba), v. 1. 2012.

PORTO, Antônio J. M. Princípios de análise do direito e da economia. In: PINHEIRO, Armando Castelar; PORTO, Antônio J. M.; SAMPAIO, Patrícia R. P (Coord.). Direito e Economia: Diálogos. Rio de Janeiro: FGV Editora, 2019. p. 28.

PINHEIRO, Armando Castelar; SADDI, Jairo. Direito, economia e mercados. Elsevier; Campus, 2006, p.4.

SAMPAIO, Patrícia R. P. Por que tutelar a livre concorrência? Notas sobre direito e economia na prevenção e repressão ao abuso do poder econômico. In: PINHEIRO, Armando Castelar; PORTO, Antônio J. M.; SAMPAIO, Patrícia R. P (Coord.). Direito e Economia: Diálogos. Rio de Janeiro: FGV Editora, 2019.

SALAMA, Bruno Meyerhof. Spread bancário e enforcement contratual: hipótese de causalidade reversa e evidência empírica. Revista Brasileira de Economia, v. 71, n. 1, p. 111$133,2017$. 
SCHÄFER, Hans-Bernd; OTT, Claus. The economics analysis of Civil Law. Edward Elgar Publisher, 2005.

STIGLITZ, Joseph; WALSH, Carl. Introdução à microeconomia. Rio de Janeiro: Campus, 2003. 